\title{
Different tissue type categories of overuse injuries to cricket fast bowlers have different severity and incidence which varies with age
}

\author{
P Blanch, ${ }^{3,4}$ M App Sc; J Orchard, ${ }^{2} \mathrm{PhD}$; A Kountouris, ${ }^{1} \mathrm{PhD}$; \\ KSims, ${ }^{1} \mathrm{PhD}$; D Beakley, ${ }^{1} \mathrm{M}$ Sports Physio \\ ${ }^{1}$ Cricket Australia, Brisbane, Australia \\ ${ }^{2}$ School of Public Health, University of Sydney, Australia \\ ${ }^{3}$ High Performance Department, Essendon Football Club, Melrose Dve, \\ Tullamarine, Australia \\ ${ }^{4}$ School of Allied Health Sciences, Griffith University, Gold Coast, Australia
}

Corresponding author: K Sims (Kevin.sims@cricket.com.au)

Background. Cricket fast bowlers have a high incidence of injury and have been the subject of previous research investigating the effects of previous injury, workload and technique. Bone stress injuries are of particular concern as they lead to prolonged absences from the game, with younger bowlers appearing to be at particular risk.

Objectives. To investigate the variation in severity and incidence of injury to different tissue types in fast bowlers and ascertain whether age is a significant risk factor for these injuries.

Methods. A retrospective analysis of match bowling exposure in 215 separate fast bowlers over a 14 -year period was undertaken. This information was amalgamated with injury surveillance data providing information on the incidence, location, tissue type and severity of injury. Age of the bowler was determined and the bowlers were stratified into five age groups to determine the influence of age on the injury variables.

Results. Younger bowlers (less than 22 years old) were 3.7-6.7 times more likely to suffer a bony injury than all the other age groups. Older bowlers (greater than 31 years old) were 2.2-2.7 times more likely to suffer a tendon injury than the 3 youngest groups.

Conclusion. This study has demonstrated that younger age is a considerable risk factor in the development of bone stress injuries in cricket fast bowlers. In addition there appears to be a higher incidence of tendon injuries in older fast bowlers although this may be explained by the current classification system of joint impingement as a tendon injury.

Keywords. Bone, tendon, sports injuries

S Afr J Sports Med 2015;27(4):108-113. DOI:10.17159/2078-516X/2015/ v27i4a436

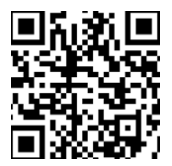

Injury to fast bowlers in cricket is one of the most significant of the sport's ongoing medical challenges. Three major risk factors have been identified in the literature. Firstly, the effect of previous injury on subsequent injury is well established across a number of sports. ${ }^{[1,2]}$ Secondly, workload and workload variation have been identified as major risk factors for fast bowling injury. Both high and low overall bowling workloads have been identified as an injury risk factor. ${ }^{[3]}$ While a high workload would seem intuitive and it has been demonstrated that bowling more than 50 overs in a match or more than 30 overs in the last innings of a match leads to an increase in injury likelihood for the subsequent month, ${ }^{[4]}$ the reason why a low workload is dangerous is less clear. Recent research suggests that low workloads are a risk factor because they are related to subsequent rapid increases (spikes) in the bowling load, which is also an identified injury risk factor. ${ }^{[5]}$

The workload studies ${ }^{[4,5]}$ tend to group all injuries together with the definition for an injury being the cessation of the current match and/or loss of subsequent competition. This places all injuries on a par and negates any measure of severity. However, this is not the case with lumbar stress fractures ${ }^{[6-9]}$ which lead to longer periods out of the game.

Bowling technique is the final of the three identified risk factors in fast bowling injuries, with biomechanical research indicating a link between excessive shoulder counter-rotation and lumbar spine stress fractures. ${ }^{[8,10]}$ Biomechanical research is often conducted on adolescent or young fast bowlers ${ }^{[6,11]}$ or does not clearly identify the demographics of the injured vs. non-injured groups. ${ }^{[10]}$ So it is unclear whether the risk factor of poor technique (excessive shoulder counterrotation) continues into the older age groups. ${ }^{[12]}$

In a previous paper these authors demonstrated that different injuries to cricket fast bowlers classified by the structure injured (bone, muscle, tendon, joint) had different types of loading histories that were either protective or risky. ${ }^{[13]} \mathrm{A}$ contrasting finding was that a high medium-term load was protective of tendon injuries but a risk factor for bony injuries. ${ }^{[13]}$ In this previous work the authors excluded the variable of age as it was found to be strongly correlated to career workload.

Due to the exclusion of age in this previous investigation, the purpose of this study was to determine the effect of age on the variation in severity and incidence of injury to different tissue types in cricket fast bowlers.

\section{Materials and methods}

Cricket Australia conducts an annual ongoing injury survey recording injuries in contracted first-class players. Methods for this survey have been described previously. ${ }^{[14]}$ The methods used for Cricket Australia injury surveillance are non-interventional, conform to the Code of Ethics of the World Medical Association (Declaration of Helsinki) and have been approved by the Cricket Australia Sports Science Sports Medicine Advisory Group.

This study amalgamated the injury data files from the previously mentioned injury surveillance program and match workload data from official scorecards (available online at http://www.espncricinfo. com/ci/engine/series/index.html) of First class (long form) and List A (short form) over 14 seasons from 1998-99 to 2011-12, inclusive.

\section{Injury definition, diagnosis and severity}

In 2005, cricket researchers published international injury consensus definitions for the sport and the methods of this survey adhere to the international definitions. ${ }^{[15]}$ The definition of a cricket injury is one that either: (1) prevents a player from being fully available for selection in a major match (which is either a first-class, two-innings per team, or limited overs, which is one-innings per team) or (2) during a major match, rendering a player unable to bat, bowl or wicket-keep when required by either the rules or the team's captain. 
Severity of the injury was determined by the cumulative numbers of matches missed which was calculated for each injury until the player returned to play.

This study concerns fast bowling injuries only and therefore includes a dataset of injuries in fast bowlers sustained either with an acute non-contact bowling mechanism or a gradual onset bowling mechanism. Injuries which were sustained either when batting or fielding were not considered as part of this study. All injuries were coded using the OSICS 9 system. ${ }^{[16]}$ The second character of the injury diagnosis was used to subcategorise the injury into muscle, bone stress, tendon or joint injuries. Further analysis of bone stress injuries were based on body part.

\section{Analysis}

Age

Age was calculated on the first day of a match, thus if a player's birthday occurred during a match the exposure of that match was included in the lower age bracket. Age was then characterised into five groups:

- <22 years old (y.o.)

- 22-25 y.o.

- 25-28 y.o.

- 28-31 y.o.

- $>31$ y.o.

The age brackets were selected to have as many even categories as possible but still maintain sufficient numbers for analysis.

\section{Exposure}

Exposure was measured by total number of overs bowled in short and long form matches by each of the age groups over the 14 seasons. Proportion of long form cricket and overs bowled per match type was also calculated, as was the average overs per match.

\section{Severity}

For each injury the number of matches lost before return to play was used as a measure of injury severity.

\section{Two-way ANOVA}

A two-way ANOVA with 'matches lost' as the dependant variable and 'age group' and 'injury type' as fixed factors was run in SPSS (Version 19).

\section{Incidence}

The number of injuries per 1000 overs of exposure was calculated across the age groups.

\section{Injury cost}

Combining the elements of severity and incidence as a measure of injury cost the authors calculated the number of matches missed per 1000 overs of exposure for the different age groups and injury types.

\section{Results}

The 14 season data allowed the authors to follow 215 individual bowlers playing in 1588 separate matches for 4014 long form and 6321 short form player matches. Over that time fast bowlers suffered a total of 563 bowling-related injuries with 62 joint injuries, 101 bone injuries, 292 muscle injuries and 108 tendon injuries that conformed to the authors' injury definition.

Table 1. Bowling exposure of different age grouped fast bowlers over 14 seasons

\begin{tabular}{|c|c|c|c|c|c|c|c|c|}
\hline \multirow[b]{2}{*}{$\begin{array}{l}\text { Age } \\
\text { (years) }\end{array}$} & \multicolumn{3}{|c|}{ Overs bowled over 14 seasons } & \multicolumn{3}{|c|}{$\begin{array}{c}\text { Matches played over } \\
14 \text { seasons }\end{array}$} & \multicolumn{2}{|c|}{$\begin{array}{l}\text { Average overs } \\
\text { per match }(\mathrm{SD})\end{array}$} \\
\hline & $\begin{array}{l}\text { Long form } \\
\text { (\% of population) }\end{array}$ & $\begin{array}{l}\text { Short form } \\
\text { (\% of population) }\end{array}$ & $\begin{array}{l}\text { Total overs } \\
\text { (\% of population) }\end{array}$ & $\begin{array}{l}\text { Long } \\
\text { form }\end{array}$ & $\begin{array}{l}\text { Short } \\
\text { form }\end{array}$ & $\begin{array}{l}\text { \%Long } \\
\text { form }\end{array}$ & $\begin{array}{l}\text { Long } \\
\text { form }\end{array}$ & $\begin{array}{l}\text { Short } \\
\text { form }\end{array}$ \\
\hline$<22$ & $10748(9.0)$ & $4118(9.3)$ & $14866(9.0)$ & 395 & 647 & 37.9 & $27.2(11)$ & $6.4(3)$ \\
\hline $22-25$ & $25596(21.3)$ & $9232(20.7)$ & $34828(21.2)$ & 877 & 1287 & 40.5 & $29.2(11)$ & $7.2(3)$ \\
\hline $25-28$ & $36900(30.7)$ & $13077(29.4)$ & 49977 (30.4) & 1217 & 1835 & 39.9 & $30.3(12)$ & $7.1(3)$ \\
\hline $28-31$ & $27012(22.5)$ & $11195(25.1)$ & $38207(23.2)$ & 879 & 1543 & 36.3 & $30.7(12)$ & $7.3(3)$ \\
\hline$>31$ & $19794(16.5)$ & $6895(16.5)$ & $26689(16.2)$ & 646 & 1009 & 39.0 & $30.6(13)$ & $6.8(3)$ \\
\hline Total & $120050(100 \%)$ & $44517(100 \%)$ & $164567(100 \%)$ & & & & & \\
\hline
\end{tabular}

Table 1 demonstrates that there are some differences in the proportional bowling load of the different age groups across matches but not within matches. The $<22$ years age group bowl around $9 \%$ of the overall deliveries, 22-25 years group 21\%, 25-28 years group $30 \%, 28-31$ years group $23.5 \%$ and the $>31$ years group $16.5 \%$. The proportional relationship of the age groups does not change much from long form to short form cricket. Interestingly, about $40 \%$
(36.3-40.5\%) of the overs bowled come from long form cricket, and this is also consistent across the age groups. Also showing strong consistency across the age groups is the average overs per match, especially in the long form of the game, with the range only being between 27-31 overs per match. So while younger players did not play as many matches the requirement for them to bowl once in a match was similar to other groups. 
Table 2 clearly illustrates that bone injuries cost considerably more lost matches than the other injury types. In the two-way ANOVA injury type was a significant factor $(\mathrm{p}<0.05)$ for lost playing time. Post-hoc analysis suggests that bone injuries were significantly $(\mathrm{p}<0.05)$ more costly than the other three subgroups (Mean difference range 5.8-9 matches lost). Tendon injuries were also significantly more costly than muscle injuries $(\mathrm{p}<0.05$, Mean difference 3.2 matches).

Age did not appear as a significant factor $(\mathrm{p}=0.35)$ in the severity (matches lost) of the different pathologies i.e. a muscle injury resulted in as many lost matches for all age groups. The interaction between the two factors fell just above the 0.05 level $(p=0.055)$ with the largest difference being between the $<22$ and 22-25 group that demonstrated significance in the post-hoc testing $(\mathrm{p}=0.023$, Mean difference 2.8 matches with the younger players taking longer on average to recover from an injury).

While the severity of the different injury types in Table 3 did not vary much across the age groups, there are some quite marked differences in the incidence of the injuries across different ages. Younger $(<22$ y.o.) and older (>31 y.o.) are 1.8-3.7 times more likely to suffer a joint injury than the other age groups. Younger bowlers are 3.7-6.7 times more likely to suffer a bony injury than all the other age groups. Younger bowlers are slightly more likely (1.4-1.6 times) to suffer a muscle injury. The incidence of tendon injuries is quite similar across the three youngest age groups and gradually increases in the 28-31 y.o. group, and is at the highest in the $>31$ y.o. group. The $>31$ y.o. group are 2.2-2.7 times more likely to suffer a tendon injury than the three youngest groups.

The combination of severity and incidence depicted in Figure 1 and Table 4 respectively provides a much better overview of the cost of the different injuries across the different age groups. Overall injury cost is clearly higher in younger bowlers, with this cost decreasing and plateauing out as they get older (22-31 y.o) and then increasing again as they go past 31 y.o. The bone injuries to young players is by far the most costly injury. This is driven not necessarily by the severity but by the much greater incidence of these injuries. These data also demonstrate the escalating cost of tendon injuries for older bowlers. This, associated with a small increase in the cost of joint injuries, makes the older group the second most costly group for injury.
Table 2. The descriptive statistics of the different age groups and injury types used in the two-way ANOVA

\begin{tabular}{|c|c|c|c|c|c|c|c|c|}
\hline \multicolumn{9}{|c|}{ Average matches lost per injury type } \\
\hline \multirow[b]{2}{*}{$\begin{array}{l}\text { Age } \\
\text { (years) }\end{array}$} & \multicolumn{2}{|c|}{ Joint } & \multicolumn{2}{|l|}{ Bone } & \multicolumn{2}{|c|}{ Muscle } & \multicolumn{2}{|c|}{ Tendon } \\
\hline & $\begin{array}{l}\text { Mean } \\
\text { (SD) }\end{array}$ & $\mathbf{N}$ & $\begin{array}{l}\text { Mean } \\
\text { (SD) }\end{array}$ & $\mathrm{N}$ & $\begin{array}{l}\text { Mean } \\
\text { (SD) }\end{array}$ & $\mathbf{N}$ & $\begin{array}{l}\text { Mean } \\
\text { (SD) }\end{array}$ & $\mathrm{N}$ \\
\hline$<22$ & $4.6(3.9)$ & 9 & $13.5(11.0)$ & 31 & $5.0(6.2)$ & 38 & $4.5(3.4)$ & 8 \\
\hline $22-25$ & $5.4(5.7)$ & 10 & $11.6(10.6)$ & 19 & $3.8(2.8)$ & 57 & $4.1(4.0)$ & 17 \\
\hline $25-28$ & $5.6(5.8)$ & 17 & $11.1(10.4)$ & 28 & $4.2(3.6)$ & 88 & $9.1(15.2)$ & 22 \\
\hline $28-31$ & $4.1(2.5)$ & 7 & $18.9(17.8)$ & 12 & $4.0(4.8)$ & 61 & $4.9(5.6)$ & 29 \\
\hline$>31$ & $6.1(11.5)$ & 18 & $14.1(10.5)$ & 11 & $3.8(3.2)$ & 48 & $10.7(13.3)$ & 32 \\
\hline All & $5.3(7.3)$ & 61 & $13.1(11.7)$ & 101 & $4.1(4.1)$ & 292 & $7.3(11.6)$ & 108 \\
\hline
\end{tabular}

Table 3. The incidence of the different injury types per 1000 overs at different age groups

\begin{tabular}{lllll}
\hline \multicolumn{2}{c}{ age groups } & \multicolumn{2}{c}{ Injuries per $\mathbf{1 0 0 0}$ overs } \\
\hline Age (years) & Joint & Bone & Muscle & Tendon \\
\hline$<22$ & 0.61 & 2.09 & 2.56 & 0.54 \\
$22-25$ & 0.29 & 0.55 & 1.64 & 0.49 \\
$25-28$ & 0.34 & 0.56 & 1.76 & 0.44 \\
$28-31$ & 0.18 & 0.31 & 1.60 & 0.76 \\
$>31$ & 0.67 & 0.41 & 1.80 & 1.20
\end{tabular}

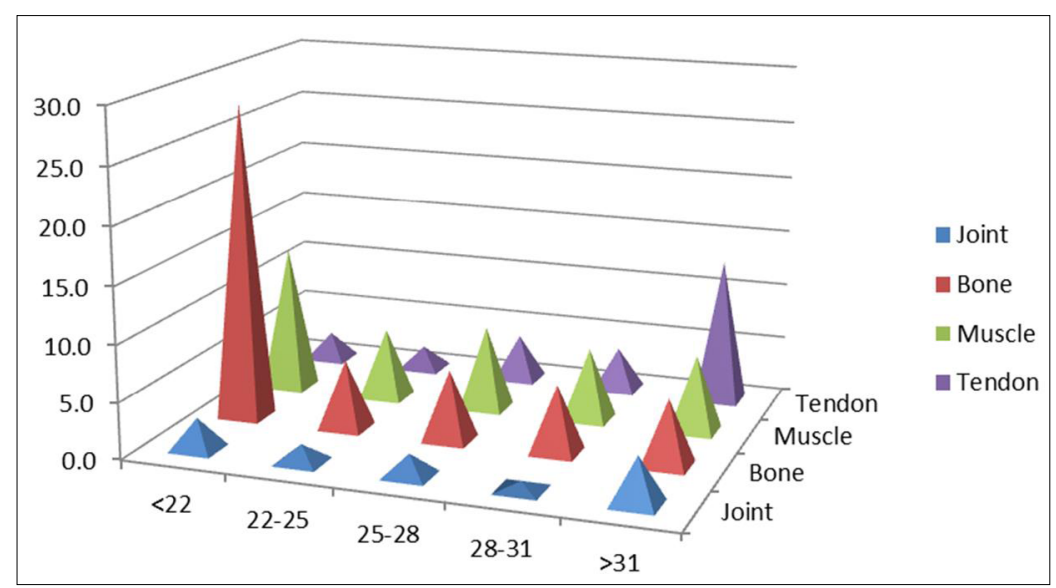

Fig. 1. The number of matches lost per 1000 overs bowled by different age groups and different injury type

Table 4. The number of matches lost per 1000 overs bowled by different age groups and different injury types plus the total matches lost per age group

\begin{tabular}{llllll}
\hline \multicolumn{5}{c}{ Matches lost per $\mathbf{1 0 0 0}$ overs bowled } \\
\hline Age (years) & Joint & Bone & Muscle & Tendon & Total \\
\hline$<22$ & 2.8 & 28.1 & 12.8 & 2.4 & 46.1 \\
$22-25$ & 1.6 & 6.1 & 6.3 & 2.0 & 15.9 \\
$25-28$ & 1.9 & 6.2 & 7.4 & 4.0 & 19.6 \\
$28-31$ & 0.8 & 5.9 & 6.4 & 3.7 & 16.9 \\
$>31$ & 4.1 & 5.8 & 6.8 & 12.8 & 29.5
\end{tabular}


Table 5. The number of bone stress injuries at different body areas by different age groups ${ }^{\star}$

\begin{tabular}{lllll}
\hline \multicolumn{5}{c}{ Number of bone injuries in different body regions } \\
\hline Age (years) & Thorax & Foot & Lumbar & Lower leg \\
\hline$<22$ & 2 & 3 & 17 & 6 \\
$22-25$ & 2 & 2 & 10 & 2 \\
$25-28$ & 3 & 6 & 14 & 3 \\
$28-31$ & 3 & 1 & 7 & 0 \\
$>31$ & 1 & 4 & 4 & 1
\end{tabular}

Table 6. The number of muscle injuries at different body areas by different age groups ${ }^{\star}$

\begin{tabular}{llllll}
\hline \multicolumn{5}{c}{ Number of muscle injuries in different body regions } \\
\hline Age (years) & Lumbar/Trunk & Hip/Groin & Thigh & Lower leg & Shoulder \\
\hline$<22$ & 20 & 4 & 9 & 2 & 1 \\
$22-25$ & 23 & 3 & 20 & 1 & 2 \\
$25-28$ & 28 & 7 & 39 & 11 & 1 \\
$28-31$ & 18 & 6 & 29 & 13 & 2 \\
$>31$ & 8 & 8 & 20 & 12 & 1 \\
$* 280$ of 292 muscle injuries occurred in the above areas; others have been excluded for brevity
\end{tabular}

Table 7. The number of tendon injuries at different body areas by different age groups*

\begin{tabular}{llllll}
\hline \multicolumn{5}{c}{ Number of muscle injuries in different body regions } \\
\hline Age (years) & Ankle & Hamstring origin & Adductor & Knee & Shoulder \\
\hline$<22$ & 1 & 0 & 0 & 2 & 0 \\
$22-25$ & 4 & 1 & 4 & 2 & 2 \\
$25-28$ & 4 & 4 & 5 & 3 & 4 \\
$28-31$ & 10 & 1 & 5 & 7 & 4 \\
$>31$ & 14 & 1 & 2 & 6 & 6 \\
$* 92$ of 102 tendon injuries are classified in these areas; others have been excluded for brevity &
\end{tabular}

\section{Discussion}

The results of this study illustrate that bony injuries have much greater severity than other types of overuse injuries in cricket fast bowlers. This, combined with a much greater incidence in younger bowlers, highlights that this is of particular importance in that group. While these two statements may not seem remarkable given the amount of research that has been done on bone injuries, especially in young fast bowlers, these authors believe this is the first study to clearly identify younger age as a risk factor in cricket fast bowlers and demonstrate the magnitude of that risk.

Younger age as a risk factor for stress fractures has been previously shown in the Israeli military ${ }^{[17]}$ Their findings showed that as age increased from 17 years through to
26 years, bony injury risk decreased by $28 \%$ per year. The findings in this present study are consistent with this trend, although it is difficult to compare the two populations, with only $3.3 \%$ ( 26 out of 796 ) of the military population over the age of 19 years, whereas this study's population was comprised of athletes of whom $98 \%$ were above the age of 19 years. Also, the type of injury suffered by the two populations is quite different. The Israeli military recruits suffered predominately from tibial stress fractures, followed by femur and then metatarsal fractures. In this study's fast bowling group the most common bony stress injury was to the lumbar spine, with the foot (tarsal and metatarsal combined) a distant second, the shank (tibia and fibula combined) less common and finally, the thorax (vertebrae, ribs and sternum combined). There were no reported femoral stress fractures (see Table 5).

The large number of lumbar spine bone stress injuries is not surprising as the incidence of these injuries in cricket fast bowlers has been reported to be between $11-55 \%^{[7,8,18]}$ and is considerably higher than the normal population. ${ }^{[19]}$ What this study demonstrates is that those bone stress injuries are clearly related to age. This is consistent with the first injury surveillance work in South African cricket which reported that all the fast bowlers who developed bone stress injuries during their three year injury surveillance period were under the age of 24 years. ${ }^{[20]}$

The higher incidence of bone injuries in younger athletes may be related to bone development and maturity. Key aspects of bone development, such as peak bone mass, bone mineral density (BMD) and bone mineral content (BMC), are age and site specific. ${ }^{[21]}$ More specifically, the major increases in BMD and BMC in the lower limb bones occur between puberty and 18 years old, whilst in the lumbar spine there are continuing increases in BMD, BMC, vertebral height and vertebral width until 25 years old. ${ }^{[2]}$ These aspects of bone structure and geometry are key determinants of bone strength and therefore key to bone stress fracture risk. ${ }^{[21]}$ It has been shown that reduced $\mathrm{BMD}$ and $\mathrm{BMC}$ are risk factors for developing stress fractures in female athletes and military recruits; ${ }^{[23,24]}$ however, the link with male athletes is less clear. Male military recruits with lower BMC are at greater risk for developing stress fractures but despite the BMD in the hip and spine being lower (3-4\%) in the stress fracture group the relationship with injury was not strong. ${ }^{[21]}$ In the current study the higher incidence of bone injuries in younger fast bowlers could be explained by skeletal immaturity, particularly as there were a high number of bone injuries in the lumbar spine that matures later than the long bones of the lower limb.

Skeletal immaturity in combination with high bowling loads is therefore the likely reason that younger fast bowlers are more vulnerable to bone injuries. While in our analysis younger bowlers make up a smaller proportion of the total overs bowled within a season once they are in a match they bowled as much as their older counterparts. This would suggest that young fast bowlers 
are more susceptible than older bowlers to bone stress injury with similar within match bowling loads. Figure 1 and Table 4 highlight that younger fast bowlers missed considerably more matches per 1000 overs bowled due to bone injury compared to other age groups and injury types.

Compared to other age groups, younger bowlers also have a greater issue with muscle injuries with a slightly higher severity (5.0 matches lost per injury) and a slightly higher incidence (2.56 per 1000 overs, see Table 3). This led to 12.8 matches lost per 1000 overs bowled (see Table 4 ) which is nearly twice that of the other age groups. The higher severity is most likely due to the type of muscle injury suffered by younger players.

Lumbar and trunk injuries represented over 55\% of the muscle injuries reported by younger bowlers. These were predominately (93\%) side strains (a tear of the attachment of the internal or external oblique muscle off the lower ribs) and this proportion of lumbar/ trunk strains from total muscle injuries dropped off as the bowling groups became older (22-25 y.o. $46 \%$, $25-28$ y.o. $33 \%, 28-31$ y.o. $30 \%$, $>31$ y.o. 14\%) (see Table 6). Anecdotally, side strains have been one of the more recalcitrant muscle injuries suffered by fast bowlers and are predominately described in cricket fast bowlers. ${ }^{[25]}$ The higher incidence of side strains in younger bowlers with a subsequent decline in incidence with age may reflect a relative weakness of the attachment of the abdominal muscles to the ribs in younger bowlers.

While joint injuries were the least expensive group of injuries for time loss there were some variations across the ages, with the youngest and oldest age group having an approximately 2-4 times higher incidence rate of the other age groups (see Table 3 ). With only 62 joint injuries spread over five age groups and five or more body areas the reason for this variation is unclear. Over 50\% (34) of the joint injuries were allocated to the lumbar spine with the others spread between the ankle, foot, elbow and knee. This is likely due to the methodological inclusion criteria in this study - "a dataset of injuries in fast bowlers sustained either with an acute non-contact bowling mechanism or a gradual onset bowling mechanism". This excludes the acute joint injuries, such as sprains from falls in the field, which often make up the predominate numbers of joint injuries in surveys. There is also perhaps a bias to attribute non-specific low back pain to a lumbar joint origin.

While it is clear that younger bowlers are the most at risk for losing game time due to injury (46.1 matches per 1000 overs bowled), older bowlers (>31y.o.) are particularly vulnerable to tendon injuries. The incidence of tendon injuries remains quite low and stable at the younger three age groups (0.44-0.54 injuries per 1000 overs) but starts to increase in the 28-31 age group (0.76 injuries per 1000 overs) and increases again in the $>31$ age group ( 1.2 injuries per 1000 overs) (see Table 3 ). The concept of increasing age being a risk factor for tendinopathy has previously been discussed in clinical commentaries, ${ }^{[26]}$ although a recent study on patella tendinopathy in elite soccer players did not support this. ${ }^{[27]}$ At present it is unclear why there is a difference between clinical perception and published epidemiological evidence.

In the current study the differences in the severity of tendon injuries are clouded by large variability in the number of games missed. There is also a problem with what is classified as a tendon injury. The increasing incidence of tendon injuries is predominantly driven by injuries to the ankle, although the knee (including quads tendon, patella tendon, hamstring insertion and iliotibial band) and the shoulder (mostly rotator cuff) are also represented (see Table 7). While the ankle distribution includes Achilles tendon injuries, 26 of these $33(79 \%)$ injuries were diagnosed by the medical staff as ankle impingement, but under the OSICS 9 system these were classified as tendon injuries. So the escalating incidence of tendon injuries can be explained by escalating ankle impingement. This is perhaps a limitation of the current coding system and needs to be considered in the future.

\section{Conclusion}

In conclusion, this study has demonstrated that younger age is a considerable risk factor in the development of bone stress injuries in cricket fast bowlers. The lumbar spine is particularly vulnerable and this is likely to be a combination of skeletal immaturity and training age capability. These authors believe that young bowlers do not have the adequate bony maturity to cope with the full demands of first-class cricket and should not be expected to withstand the same volume as older, more seasoned bowlers. The younger fast bowler also is more susceptible to side strain injury which is likely to be for the same reasons as mentioned above. Finally, while under the classification system used in this study (OSICS 9), tendon injuries increase with older age, which appears to be driven by the classification of ankle impingement as a tendon injury.

\section{References}

1. Orchard JW, James T, Portus MR. Injuries to elite male cricketers in Australia over a 10-year period. J Sci Med Sport 2006;9(6):459-467. [http://dx.doi.org/10.1016/j. sams.2006.05.001]

2. Gabbe BJ, Bennell KL, Finch CF, et al. Predictors of hamstring injury at the elite level of Australian football. Scand J Med Sci Sports 2006;16(1):7-13. [http://dx.doi. org/10.1111/j.1600-0838.2005.00441.x]

3. Dennis R, Farhart P, Goumas C, et al. Bowling workload and the risk of injury in elite cricket fast bowlers. J Sci Med Sport 2003;6(3)359-367. [http://dx.doi.org/10.1016/ S1440-2440(03)80031-2] [14609154]

4. Orchard JW, James T, Portus M, et al. Fast bowlers in cricket demonstrate up to 3- to 4 -week delay between high workloads and increased risk of injury. Am J Sports Med 2009;37(6):1186-1192. [http://dx.doi.org/10.1177/0363546509332430]

5. Hulin BT, Gabbett TJ, Blanch P, et al. Spikes in acute workload are associated with increased injury risk in elite cricket fast bowlers. Br J Sports Med 2014;48(8):708-712. [http://dx.doi.org/10.1136/bjsports-2013-092524]

6. Crewe H, Elliott B, Couanis G, et al. The lumbar spine of the young cricket fast bowler: an MRI study. J Sci Med Sport 2012;15(3):190-194. [http://dx.doi. org/10.1016/j.sams.2011.11.251]

7. Engstrom CM, Walker DG. Pars interarticularis stress lesions in the lumbar spine of cricket fast bowlers. Med Sci Sports Exerc 2007;39(1):28-33. [http://dx.doi. org/10.1249/01.mss.0000241642.82725.ac]

8. Foster D, John D, Elliott B, et al. Back injuries to fast bowlers in cricket: a prospective study. Br J Sports Med 1989;23(3):150-154. [http://dx.doi.org/10.1136/ bjsm.23.3.150] PMID: 2620228. [1478681]

9. Ranson CA, Burnett AF, Kerslake RW. Injuries to the lower back in elite fast bowlers: acute stress changes on MRI predict stress fracture. J Bone Joint Surg Br 2010;92(12): 1664-1668. [http://dx.doi.org/10.1302/0301-620X.92B12.24913]

10. Portus M, Mason BR, Elliott BC, et al. Technique factors related to ball release speed and trunk injuries in high performance cricket fast bowlers. Sports Biomech 2004;3(2):263-284. [http://dx.doi.org/10.1080/14763140408522845]

11. Ranson CA, Burnett AF, King M, et al. The relationship between bowling action classification and three-dimensional lower trunk motion in fast bowlers in cricket. J Sports Sci 2008;26(3):267-276. [http://dx.doi.org/10.1080/02640410701501671]

12. Ranson C, Burnett A, King M, et al. Acute lumbar stress injury, trunk kinematics, lumbar MRI and paraspinal morphology in fast bowlers in cricket. Proceedings of ISBS Conference. 2008. Seoul, South Korea, p. 4.

13. Orchard J, Blanch P, Paoloni J, et al., Different tissue types exhibit variations in workload patterns as risk factors for injury. Br J Sports Med 2014; Submitted. [3963545] 
14. Orchard J, James T, Portus M. Injuries to elite male cricketers in Australia over a 10-year period. J Sci Med Sport 2006;9(6):459-467. [http://dx.doi.org/10.1016/j. sams.2006.05.001]

15. Orchard J, Newman D, Stretch R, et al. Methods for injury surveillance in international cricket. Br J Sports Med 2005;39(4):E22. [http://dx.doi.org/10.1136/ bjsm.2004.012732] PMID: 15793080. [1725193]

16. Orchard J, Rae K, Brooks J, et al. Revision, uptake and coding issues related to the open access Orchard Sports Injury Classification System (OSICS) versions 8, 9 and 10.1. Open Access J Sports Med 2010;1:207-214. [http://dx.doi.org/10.2147/OAJSM. S7715] [3781871]

17. Milgrom C, Finestone A, Shlamkovitch N, et al. Youth is a risk factor for stres fracture. A study of 783 infantry recruits. J Bone Joint Surg Br 1994;76(1):20-22 PMID: 8300674.

18. Hardcastle P, Annear P, Foster DH, et al. Spinal abnormalities in young fast bowlers. J Bone Joint Surg Br 1992;74(3):421-425. PMID: 1587894.

19. Beutler WJ, Fredrickson BE, Murtland A, et al. The natural history of spondylolysis and spondylolisthesis: 45-year follow-up evaluation. Spine (Phila Pa 1976) 2003;28(10) 1027-1035; discussion 1035. [http://dx.doi.org/10.1097/01.BRS.0000061992.98108.A0]

20. Stretch RA. Cricket injuries: a longitudinal study of the nature of injuries to South African cricketers. Br J Sports Med 2003;37(3):250-253; discussion 253. [http:// dx.doi.org/10.1136/bjsm.37.3.250] [1724632]
21. Cosman F, Ruffing J, Zion M, et al. Determinants of stress fracture risk in United States Military Academy cadets. Bone 2013;55(2):359-366. [http://dx.doi.org/10.1016/j. bone.2013.04.011]

22. Walsh JS, Henry YM, Fatayerji D, et al. Lumbar spine peak bone mass and bone turnover in men and women: a longitudinal study. Osteoporos Int 2009;20(3):355-362. [http://dx.doi.org/10.1007/s00198-008-0672-5]

23. Loud KJ, Micheli LJ, Bristol S, et al. Family history predicts stress fracture in active female adolescents. Pediatrics 2007;120(2):e364-372. [http://dx.doi.org/10.1542/ peds.2006-2145] [3200550]

24. Pouilles JM, Bernard J, Tremollieres F, et al. Femoral bone-density in young maleadults with stress-fractures. Bone 1989;10(2):105-108. [http://dx.doi.org/10.1016.87563282(89)90006-9]

25. Obaid H, Nealon A, Connell D. Sonographic appearance of side strain injury. AJR Am J Roentgenol 2008;191(6):W264-W267. [http://dx.doi.org/10.2214/ajr.07.3381]

26. Rees J, Wilson A, Wolman R Current concepts in the management of tendon disorders. Rheumatology (Oxford) 2006;45(5):508-521. [http://dx.doi.org/10.1093/ rheumatology/kel046] [16490749]

27. Hägglund M, Zwerver J, Ekstrand J. Epidemiology of patellar tendinopathy in elite male soccer players. Am J Sports Med 2011;39(9):1906-1911. [http://dx.doi org/10.1177/0363546511408877] 